\title{
Jim Goodridge Memorial
}

\author{
Michael L. ANDERSON \\ California State Climatologist, California Department of Water Resources
}

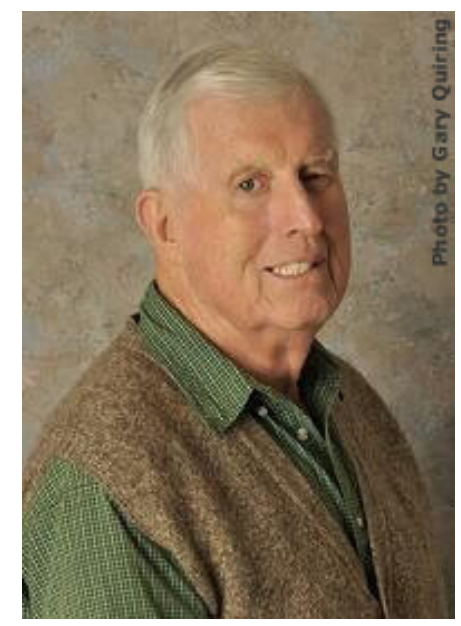

Jim Goodridge, California's first state climatologist, passed away on January 5, 2020 at the age of 92. Jim was one of the founding members of the American Association of State Climatologists (AASC) and served on committees during the organization's early years. His career started in the United States Weather Bureau in Sacramento, CA in November of 1950 during a storm. As he said, "from that moment I was hooked". Not caring for the operational shift-work hours, he moved on to the United States Army Corps of Engineers and then onto the California Department of Water Resources (DWR) by 1953 .

While serving as the California State Climatologist, he contributed to several state reports, served on the AASC nominations committee and the state programs committee. Upon his retirement in 1984, he was made an associate member of the AASC.

During Jim's tenure at DWR, he developed a volunteer observing network and traded precipitation analysis for data from any local agency with which he could connect. Jim developed calendars identifying notable precipitation events, reports on significant precipitation events in California's history, and developed a state-level precipitation depth-duration-frequency report that he would update regularly.

His passion for data and its analysis continued for the rest of his life. He retired from DWR in 1984. I was introduced to Jim when I became State Climatologist in 2005. At that time he lived in Chico, CA and continued to collect, review, and analyze data part time for DWR and said he would send me updates.

True to his work, twice a year he would send me updates of all the data he collected (e.g., temperature, precipitation, upwelling, solar radiation, and more) on a $\mathrm{CD}$ and later flash drives. The last one I received was in December 2019.

In 2005, he was awarded a special recognition award by the California Extreme Precipitation Symposium for his extensive work in precipitation analysis. The combination of his passion for data and his gracious manner was magnetic, drawing others into his sphere that led to many fruitful collaborations and publications. He was a valuable mentor to me from the time I stepped into this role and I will miss him and his updates sorely. 